AperTO - Archivio Istituzionale Open Access dell'Università di Torino

\title{
Ferryl $(\mathrm{Fe}=0)$ termination of the hematite alpha-Fe203(0001) surface
}

\section{This is the author's manuscript}

Original Citation:

\section{Availability:}

This version is available http://hdl.handle.net/2318/10992 since

Publisher:

American Institute of Physics:2 Huntington Quadrangle, Suite 1NO1:Melville, NY 11747:(800)344-6902,

Published version:

DOI:10.1103/PhysRevLett.94.166101

Terms of use:

Open Access

Anyone can freely access the full text of works made available as "Open Access". Works made available under a Creative Commons license can be used according to the terms and conditions of said license. Use of all other works requires consent of the right holder (author or publisher) if not exempted from copyright protection by the applicable law. 


\title{
Ferryl $(\mathrm{Fe}=\mathrm{O})$ Termination of the Hematite $\alpha-\mathrm{Fe}_{2} \mathrm{O}_{3}(0001)$ Surface
}

\author{
C. Lemire, ${ }^{1}$ S. Bertarione, ${ }^{2}$ A. Zecchina, ${ }^{2}$ D. Scarano, ${ }^{3}$ A. Chaka, ${ }^{3}$ S. Shaikhutdinov, ${ }^{1, *}$ and H.-J. Freund ${ }^{1}$ \\ ${ }^{1}$ Departmernt of Chemical Physics, Fritz-Haber Institute of the Max-Planck Society, Faradayweg 4-6, 14195 Berlin, Germany \\ ${ }^{2}$ Università Dipartimento Chimica IFM, Via Pietro Giuria 7, Torino, Italy 10125 \\ ${ }^{3}$ National Institute of Standards and Technology, 100 Bureau Drive, Stop 8380, Gaithersburg, Maryland 20899-8380, USA
}

(Received 19 November 2004; published 26 April 2005)

\begin{abstract}
Using scanning tunneling microscopy and infrared reflection absorption spectroscopy we have observed that the $\alpha$ - $\mathrm{Fe}_{2} \mathrm{O}_{3}(0001)$ surface exhibits ferryl $(\mathrm{Fe}=\mathrm{O})$ groups, which may coexist with domains of the Fe-terminated surface. We therefore fully support $a b$ initio calculations recently reported in the literature [W. Bergmeyer, H. Schweiger, and E. Wimmer, Phys. Rev. B 69, 195409 (2004)]. The close similarity to the results on the (0001) surfaces of $\mathrm{Cr}_{2} \mathrm{O}_{3}$ and $\mathrm{V}_{2} \mathrm{O}_{3}$ strongly suggests that the $M=\mathrm{O}$ termination under certain oxygen pressure conditions is the most stable for the close-packed surfaces of transition metal oxides with the corundum structure.
\end{abstract}

DOI: 10.1103/PhysRevLett.94.166101

PACS numbers: 68.47.Gh, 68.35.Bs, 68.49.Uv

Surface structures of transition metal oxides often deviate from those expected from the cleavage of the oxide bulk. In particular, it has been shown that oxides with corundum structure (such as $\mathrm{Cr}_{2} \mathrm{O}_{3}, \mathrm{~V}_{2} \mathrm{O}_{3}$ ) may be terminated by metal-oxygen double bond species $(\mathrm{Cr}=\mathrm{O}$, $\mathrm{V}=\mathrm{O}$ ) absent in the bulk [1-3]. From simple electrostatic considerations, the stable corundum surface is expected to be the metal-terminated stoichiometric surface $M-\mathrm{O}_{3}-M-M-R$ (the subscript denotes the number of atoms in a layer in the unit cell; see Fig. 1), which has the same number of cations above and below the oxygen anion layer. It has been theoretically predicted that the surface structure of $\alpha-\mathrm{Fe}_{2} \mathrm{O}_{3}(0001)$, which is isostructural to chromia and vanadia, should depend on the ambient oxygen pressure such that, at high pressures, an oxygen-terminated surface becomes lower in energy than the iron-terminated layer that is stable at low $\mathrm{O}_{2}$ pressures [4]. Both surfaces are unreconstructed and stabilized by strong relaxations. This hypothesis has been substantiated by scanning tunneling microscopy (STM) studies of $\mathrm{Fe}_{2} \mathrm{O}_{3}(0001)$ films prepared at different oxygen pressures [5]. Two different surfaces were observed, which were assigned to the $\mathrm{O}_{3}$ and $\mathrm{Fe}$ terminations according to the theoretical predictions. However, based on dynamical LEED studies of the films, Ketteler et al. [6] suggested that the surface, prepared at $10^{-5}$ mbar $\mathrm{O}_{2}$, may be hydroxyl terminated due to reactions with traces of water. On the other hand, Chambers and $\mathrm{Yi}$, employing $\mathrm{x}$-ray photoelectron diffraction on the films prepared by oxygen plasma assisted epitaxy, conclude that the surface is $\mathrm{Fe}$ terminated despite the highly oxidizing conditions used [7]. Recently, Bergmeyer et al. [8] and Rohrbach et al. [9] theoretically predicted relative stability of ferryl $(\mathrm{Fe}=\mathrm{O})$ groups on the hematite surface, which is rather surprising. Indeed, while $\mathrm{Cr}=\mathrm{O}$ and $\mathrm{V}=\mathrm{O}$ double bonds are well known species in chemistry of $\mathrm{Cr}$ and $\mathrm{V}$ compounds, $\mathrm{Fe}=\mathrm{O}$ species are very rare and mainly considered as an active center in heme containing enzymes.
In this Letter, using infrared reflection absorption spectroscopy (IRAS), we present the first experimental evidence that the ferryl groups indeed exist on the $\alpha-\mathrm{Fe}_{2} \mathrm{O}_{3}(0001)$ surface. We use density functional theory (DFT) to calculate the vibrational properties of the ferryl groups.

The bulk structure of $\alpha-\mathrm{Fe}_{2} \mathrm{O}_{3}(0001)$ is schematically shown in Fig. 1. Along the axis normal to the surface the stacking sequence of hexagonal iron and oxygen layers can
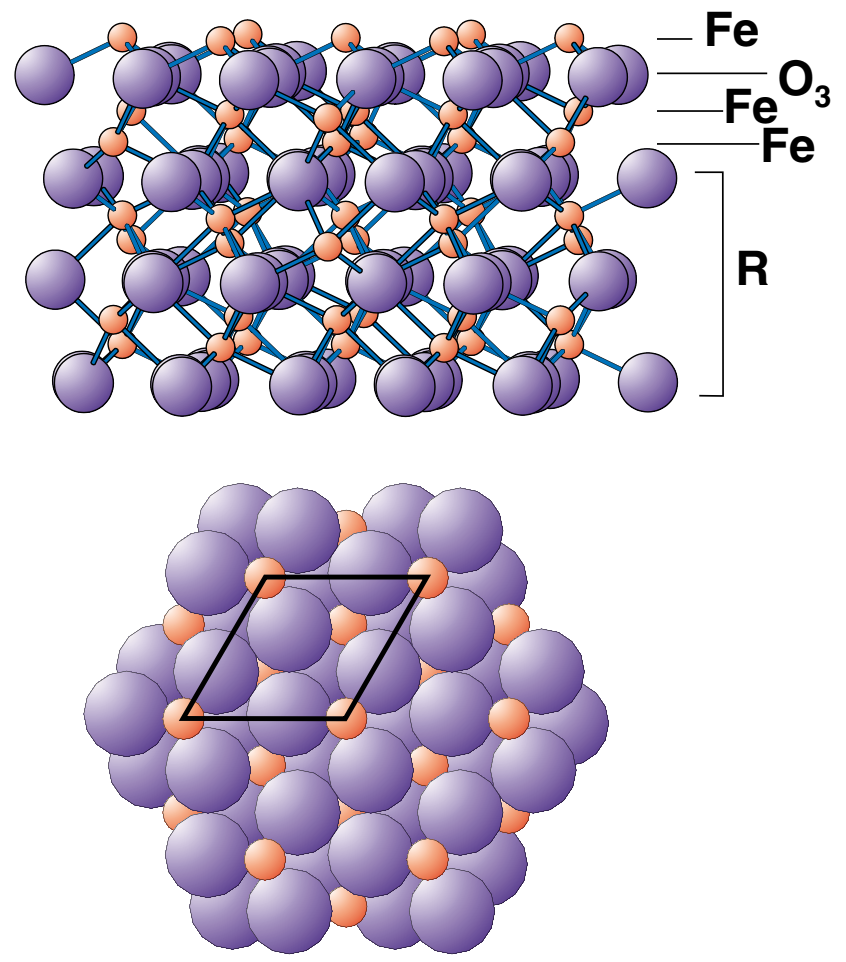

FIG. 1 (color online). Perspective side and top views of $\alpha-\mathrm{Fe}_{2} \mathrm{O}_{3}(0001)$. The Fe-terminated surface is shown, with the unit cell indicated. 
be described as $\cdots \mathrm{Fe}-\mathrm{O}_{3}-\mathrm{Fe}-\mathrm{Fe}-\mathrm{O}_{3}-\mathrm{Fe} \cdots$. The $\mathrm{Fe}$ layer forms a $(\sqrt{3} x \sqrt{3}) R 30^{\circ}$ structure with respect to the closepacked oxygen layer, resulting in an $\mathrm{Fe}-\mathrm{Fe}$ distance of $5.03 \AA$, which is the lattice constant of the surface unit cell. The distance between two identical planes is $2.29 \AA$.

To study the hematite surfaces, we prepared well ordered $\mathrm{Fe}_{2} \mathrm{O}_{3}(0001)$ films on a $\mathrm{Pt}(111)$ substrate in $10^{-3}-1$ mbar of $\mathrm{O}_{2}$ at $\sim 1050 \mathrm{~K}$ [5]. The films of 5$7 \mathrm{~nm}$ in thickness exhibited sharp low energy electron diffraction patterns. In one chamber, the samples were studied with STM at room temperature and temperature programmed desorption (TPD) of CO. In a different chamber, we employed IRAS and TPD. In both chambers, we used the same preparation conditions and obtained essentially identical CO TPD spectra, which allowed us to combine results from the two chambers.

Theoretical calculations were performed on bulk and slab geometries in the conventional hexagonal unit cell representation using spin-polarized all-electron first principles DFT and DNP (double numeric with polarization) basis sets as implemented in the $\mathrm{Dmol}^{3}$ program [10]. The generalized gradient approximation [11] was used to solve the Kohn-Sham equations. $k$-point sampling was performed on a $5 \times 5$ mesh and checked with a $12 \times 12$ mesh. The lowest energy structure was found to be antiferromagnetic within iron double layers. Symmetric slabs were 18 atomic layers thick and separated by $10 \AA$ of vacuum.

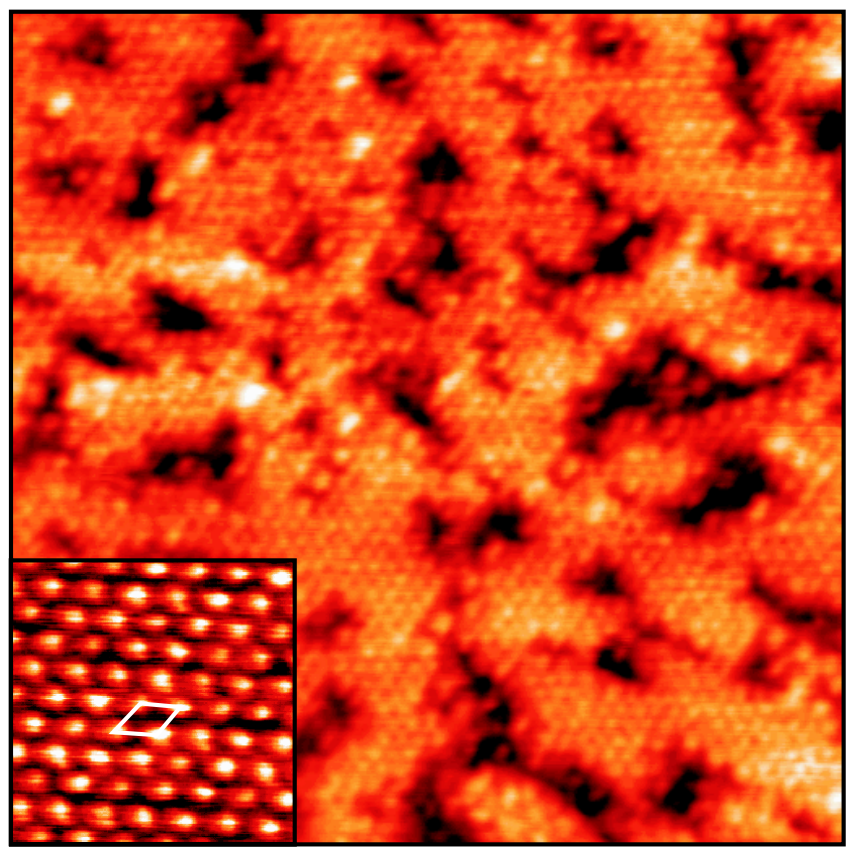

FIG. 2 (color online). High resolution STM image of the $\mathrm{Fe}_{2} \mathrm{O}_{3}(0001)$ film prepared in $10^{-2}$ mbar of $\mathrm{O}_{2}$ at $1020 \mathrm{~K}$ (size $30 \times 30 \mathrm{~nm}^{2}, V_{t}=1.4 \mathrm{~V}, I=1 \mathrm{nA}$ ). The lattice of protrusions with a $\sim 5 \AA$ periodicity is clearly seen in the inset (size $3 \times 3 \mathrm{~nm}^{2}$ ). The unit cell is indicated.
Large scale STM images of the $\mathrm{Fe}_{2} \mathrm{O}_{3}(0001)$ films revealed wide flat terraces separated by monatomic steps $\sim 2.3 \AA$ in height or multiples thereof. Atomic-resolution STM images of the films revealed a $\sim 5 \AA$ periodicity, as shown in Fig. 2. However, the terraces exhibited a heterogeneous surface with a random placement of small depressed areas. The depth of these areas is $1-1.5 \AA$ (depending on the tunneling conditions), i.e., significantly smaller than the $2.3 \AA$ for the monatomic step, and should therefore be assigned to a domain, exhibiting different termination.

Identically prepared samples were studied by IRAS, in which we measure relative intensities referenced to a baseline from a clean substrate or, in the case of adsorption studies, from the sample measured right before gas exposure.

Curve (1) in Fig. 3(a) shows the IRAS spectrum obtained for the $\mathrm{Fe}_{2} \mathrm{O}_{3}(0001)$ surface, prepared in $5 \times 10^{-2} \mathrm{mbar}$ $\mathrm{O}_{2}$ at $1040 \mathrm{~K}$, and referenced to the $\mathrm{Pt}(111)$ substrate. The only feature observed in survey spectra is a peak at $989 \mathrm{~cm}^{-1}$. A difference spectrum (2) comparing two sur-
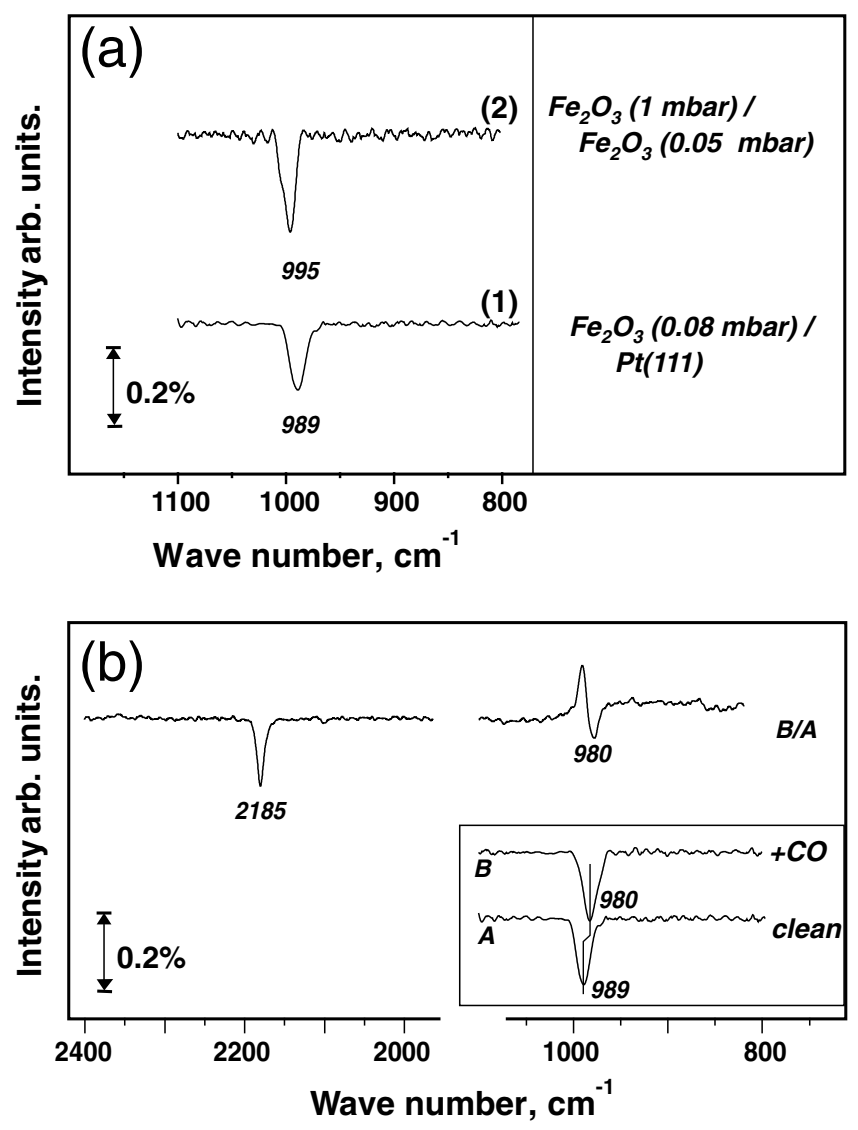

FIG. 3. (a) IRAS spectra of the $\mathrm{Fe}_{2} \mathrm{O}_{3}(0001)$ films. (b) $\mathrm{CO}$ IRAS spectrum of the $\mathrm{Fe}_{2} \mathrm{O}_{3}$ sample (1) shown in (a) after exposing to $1.5 \mathrm{~L}$ of $\mathrm{CO}$ at $90 \mathrm{~K}$. The unusual peak shape at $\sim 980 \mathrm{~cm}^{-1}$ results from a shift of the oxide absorption band induced by $\mathrm{CO}$ adsorption, as shown in the inset. 
faces prepared at different $\mathrm{O}_{2}$ pressures ( 0.01 and $1 \mathrm{mbar}$ ) clearly shows that the IR absorption in this region becomes stronger with increasing oxygen pressure.

The absorption bands at around $1000 \mathrm{~cm}^{-1}$ are characteristic for the stretching vibrations of the metal-oxygen double bond observed in $\mathrm{V}_{2} \mathrm{O}_{5}, \mathrm{H}-\mathrm{Nb}_{2} \mathrm{O}_{5}$, and $\mathrm{MoO}_{3}$ [12], where $M=\mathrm{O}$ species are present in the bulk. However, it has recently been shown that $\mathrm{Cr}_{2} \mathrm{O}_{3}(0001)$ and $\mathrm{V}_{2} \mathrm{O}_{3}(0001)$ films may also expose chromyl $(\mathrm{Cr}=\mathrm{O})$ and vanadyl $(\mathrm{V}=\mathrm{O})$ groups on the surface, thus resulting in IRAS signals at 1015 and $1040 \mathrm{~cm}^{-1}$, respectively [1-3]. In particular, the presence of vanadyl species on the $\mathrm{V}_{2} \mathrm{O}_{3}$ films has been additionally proven by angular resolved photoelectron spectroscopy [3] and supported by theoretical calculations [13].

Our DFT calculations on the ferryl-terminated surface found a stretching frequency of $981 \mathrm{~cm}^{-1}$, in excellent agreement with the observed frequency and providing strong support for the $\mathrm{Fe}=\mathrm{O}$ assignment. The calculations show that the ferryl oxygen is $1.58 \AA$ directly on top of the iron cations, which is consistent with the atomically resolved STM images, showing that the protrusions in domains with different terminations are in registry but of different corrugation amplitudes (for example, see Fig. 3 in [5]). Indeed, these protrusions are attributed to the $\mathrm{Fe}$ cations as the states near the Fermi level, probed by STM, are determined by Fe $3 d$ orbitals [4]. Since ferryl is formed by placing oxygen on top of Fe, both surfaces must be in registry. The calculated relaxation of the ferryl iron from the bulk position is $\sim-20 \%$, which is considerably less than the $\sim-65 \%$ of the clean $\mathrm{Fe}-\mathrm{O}_{3}-\mathrm{Fe}_{2}-R$ surface. Hence the height difference between the ferryl oxygen atom and the relaxed surface Fe cation on the clean surface is $1.96 \AA$, i.e., larger than observed by STM (1-1.5 $\AA$ ). However, oxygen must screen the electron density of Fe, thus reducing the apparent height difference and also explaining the lower atomic corrugation over the $\mathrm{Fe}=\mathrm{O}$ surface [5].

We have further studied the $\mathrm{Fe}_{2} \mathrm{O}_{3}(0001)$ surface using adsorption of $\mathrm{CO}$ as a probe molecule. The $\mathrm{CO}$ TPD spectra for all films studied showed only a single desorption peak at $\sim 130 \mathrm{~K}$, indicating that $\mathrm{CO}$ adsorbs on the $\mathrm{Fe}_{2} \mathrm{O}_{3}(0001)$ surface more weakly than on the $\mathrm{Fe}$ terminated $\mathrm{Fe}_{3} \mathrm{O}_{4}(111)$ films $\left(T_{\text {des }} \sim 180 \mathrm{~K}\right.$ [14]). CO IRAS spectra show signals in two distinct regions: the peak at $2185 \mathrm{~cm}^{-1}$ and the signal at $\sim 980 \mathrm{~cm}^{-1}$ [see Fig. 3(b)]. The peak at $2185 \mathrm{~cm}^{-1}$ can be assigned to the stretching vibration of $\mathrm{CO}$ adsorbed on the $\mathrm{Fe}^{3+}$ ions $[12,14-16]$. The unusual shape of the signal at $980 \mathrm{~cm}^{-1}$ results from a $\mathrm{CO}$ induced shift of the $\mathrm{Fe}=\mathrm{O}$ vibration frequency. This is illustrated in the inset in Fig. 3(b): the signal at $989 \mathrm{~cm}^{-1}$ on the clean film is shifted by $9 \mathrm{~cm}^{-1}$ to lower wave numbers upon $\mathrm{CO}$ adsorption. Interestingly, such a phenomenon is essentially identical to that observed for vanadia particles deposited on alumina and silica films
[17]. It seems likely that it involves direct interactions between $\mathrm{CO}$ and $\mathrm{Fe}=\mathrm{O}$ species at the border of two domains with different terminations.

$\mathrm{CO}$ adsorption experiments also showed that the hematite films were not completely covered by the ferryl groups, which is in line with the STM studies showing the heterogeneity of the hematite film surface. When the intensities of the $\mathrm{CO}$ signal at $2185 \mathrm{~cm}^{-1}$ and of the $\mathrm{Fe}=\mathrm{O}$ signal at $989 \mathrm{~cm}^{-1}$ (on the clean film) were compared to those observed for the metal and $M=\mathrm{O}$ terminated surfaces of $\mathrm{Cr}_{2} \mathrm{O}_{3}$ and $\mathrm{V}_{2} \mathrm{O}_{3}$ films previously studied [1,3], then the $\mathrm{Fe}=\mathrm{O}$ coverage could be roughly estimated to be around $0.4 \mathrm{ML}$ (referring to the Fe-terminated surface, depicted in Fig. 1, as 1 monolayer).

In contrast to vanadium and chromium oxides, where the existence of $M=\mathrm{O}$ species are well documented in the literature for powdered samples using conventional Fourier transform infrared (FTIR) spectroscopy, results for iron oxides are very limited $[12,15]$. In order to compare the results for the well ordered films and polycrystalline samples, we have performed IR studies on $\mathrm{Fe}_{2} \mathrm{O}_{3}$ powders. Figure 4 shows the $800-1200 \mathrm{~cm}^{-1}$ region of the spectra for the sample prepared at $973 \mathrm{~K}$ in 40 mbar of $\mathrm{O}_{2}$ and another at $1023 \mathrm{~K}$ in $5 \times 10^{-2} \mathrm{mbar}$ of $\mathrm{O}_{2}$, i.e., under the same conditions as the $\mathrm{Fe}_{2} \mathrm{O}_{3}(0001)$ films studied by IRAS. Both samples showed only a hematite phase in the $\mathrm{x}$-ray diffraction patterns and a typical needlelike morphol-

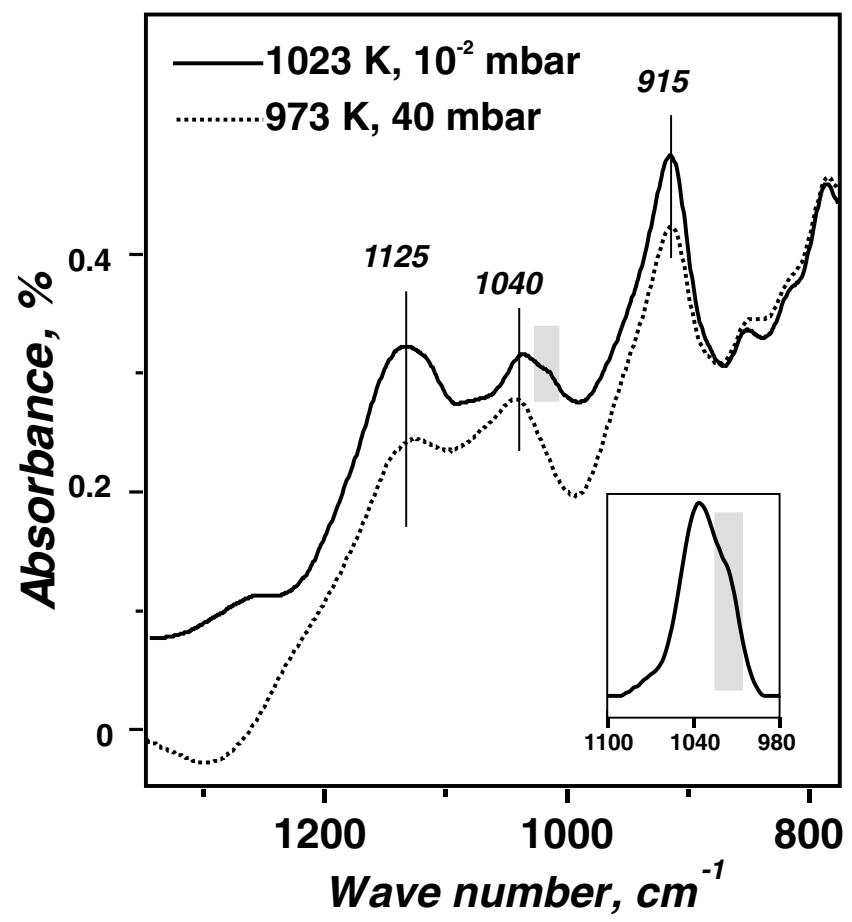

FIG. 4. IR spectra of the polycrystalline $\mathrm{Fe}_{2} \mathrm{O}_{3}$ samples prepared at $973 \mathrm{~K}$ in 40 mbar of $\mathrm{O}_{2}$ (dashed line) and at $1023 \mathrm{~K}$ in $5 \times 10^{-2}$ mbar of $\mathrm{O}_{2}$ (solid line). The $\mathrm{Fe}=\mathrm{O}$ region is expanded in the inset. 
ogy of the crystallites as revealed by electron microscopy $[16,18]$.

The absorption bands at 915,1040 , and $1125 \mathrm{~cm}^{-1}$ can be assigned to multiple phonon excitations $[19,20]$. (The fact that these bands are not observed in the IRAS spectra of the films is due to the small thickness of the films and the large contribution of the bulk absorption in IR spectra of powders in a transmission mode.) Comparing the two spectra shown in Fig. 4, one can see the presence of the prominent shoulder at $\sim 1015 \mathrm{~cm}^{-1}$ for the samples prepared under the same conditions as the thin films. We have assigned this feature to the ferryl species. The $\sim 25 \mathrm{~cm}^{-1}$ difference between the frequencies observed by IRAS for the film and by FTIR for the powder is not surprising. It has been shown for $\alpha-\mathrm{Cr}_{2} \mathrm{O}_{3}$ powders that the $\mathrm{Cr}=\mathrm{O}$ stretching frequency depends on "coordinative and ligand heterogeneity" of $\mathrm{Cr}$ ions and varies in the range 990-1040 $\mathrm{cm}^{-1}$ [21], whereas its value for the chromia films is $1005 \mathrm{~cm}^{-1}$ [1]. In addition, the difference between thin films and powdered systems can be attributed to the interaction with bulk phonons in powders as well as with surface species. (Note that the FTIR studies on powder are not performed under UHV conditions.) Since the surface of the hematite crystallites is predominantly the prismatic (110) planes and not the basal (0001) plane [15], the intensity of this feature at $1015 \mathrm{~cm}^{-1}$ is relatively small. This shoulder appears to be absent for the sample treated at high oxygen pressure, indicating that the ferryl species is less stable under these conditions.

Using the DFT-based $a b$ initio thermodynamics methodology [22], we have calculated the surface free energies as a function of oxygen pressure. Our calculations show that the $\mathrm{Fe}=\mathrm{O}$ surface becomes the most stable above an oxygen chemical potential of $-1.4 \mathrm{eV}$, which corresponds to a $p\left(\mathrm{O}_{2}\right)$ of $1 \mathrm{mbar}$ at $1040 \mathrm{~K}$ and $10^{-2} \mathrm{mbar}$ at $870 \mathrm{~K}$, i.e., in quantitative agreement with our experiments.

The chemistry of the $M=\mathrm{O}$ species on the oxide surface is the subject of the on-going investigations in different groups. Our own results show that vanadyl and chromyl species present on the $\mathrm{M}_{2} \mathrm{O}_{3}(0001)$ surfaces are essentially inert in adsorption of many molecules such as $\mathrm{CO}, \mathrm{CO}_{2}$, and $\mathrm{H}_{2}[1,23]$. However, this is not obvious for the ferryl species. It is well documented that ferryl is a key species or intermediate in the heme containing enzymes, which efficiently oxygenate and hydroxylate saturated hydrocarbons by molecular oxygen [24]. Therefore, one can expect that ferryl species on the oxide surface may be active, for example, in selective oxidation and dehydrogenation reactions.

In summary, our experimental and theoretical results provide strong evidence that the $\mathrm{Fe}_{2} \mathrm{O}_{3}(0001)$ surface can form ferryl $(\mathrm{Fe}=\mathrm{O})$ groups, which coexist with domains of the Fe-terminated surface. The close similarity to the re- sults on the (0001) surfaces of $\mathrm{Cr}_{2} \mathrm{O}_{3}$ and $\mathrm{V}_{2} \mathrm{O}_{3}$ strongly suggests that the $M=\mathrm{O}$ termination at certain oxygen pressure is the most stable for the surfaces of transition metal oxides with corundum structure.

*Corresponding author.

Email: shaikhutdinov@fhi-berlin.mpg.de

[1] B. Dillmann, F. Rohr, O. Seiferth et al., Faraday Discuss. 105, 295 (1996).

[2] O. Seiferth, K. Wolter, B. Dillmann et al., Surf. Sci. 421, 176 (1999).

[3] A.-C. Dupuis, M. Abu Haija, B. Richter, H. Kuhlenbeck, and H.-J. Freund, Surf. Sci. 539, 99 (2003).

[4] X.-G. Wang, W. Weiss, S. K. Shaikhutdinov et al., Phys. Rev. Lett. 81, 1038 (1998).

[5] S. K. Shaikhutdinov and W. Weiss, Surf. Sci. Lett. 432, L627 (1999).

[6] G. Ketteler, W. Weiss, and W. Ranke, Surf. Rev. Lett. 8, 661 (2001).

[7] S. Chambers and S. I. Yi, Surf. Sci. Lett. 439, L785 (1999).

[8] W. Bergmeyer, H. Schweiger, and E. Wimmer, Phys. Rev. B 69, 195409 (2004).

[9] A. Rohrbach, J. Hafner, and G. Kresse, Phys. Rev. B 70, 125426 (2004).

[10] B. Delley, J. Chem. Phys. 92, 508 (1990); 113, 7756 (2000). Dmol ${ }^{3}$ is available from Accelrys, Inc.

[11] J. P. Perdew, K. Burke, and M. Ernzerhof, Phys. Rev. Lett. 77, 3865 (1996).

[12] A. A. Davydov, Infrared Spectroscopy of Adsorbed Species on the Surface of Transition Metal Oxides (Wiley, New York, 1984).

[13] K. Hermann and M. Witko, in The Chemical Physics of Solid Surfaces, edited by D. A. King and D. P. Woodruff (Elsevier, New York, 2001), p. 136.

[14] C. Lemire, R. Meyer, V. Henrich, S. K. Shaikhutdinov, and H.-J. Freund, Surf. Sci. 572 , 103 (2004).

[15] A. Zecchina, D. Scarano, S. Bordiga et al., Catal Today 27, 403 (1996).

[16] A. Zecchina, D. Scarano, and A. Reller, J. Chem. Soc., Faraday Trans. 1 84, 2327 (1988).

[17] N. Magg, B. Immaraporn, J. B. Giorgi et al., J. Catal. 226, 88 (2004).

[18] We thank G. Weinberg and F. Girgsdies (FHI) for structural characterization of hematite powders.

[19] Q. Guo and P. J. Møller, Surf. Sci. Lett. 340, L999 (1995).

[20] M. A. Henderson, Surf. Sci. 515, 253 (2002).

[21] A. Zecchina, S. Coluccia, L.Cerruti, and E. Borelo, J. Phys. Chem. 75, 2783 (1971).

[22] K. Reuter and M. Scheffler, Phys. Rev. B 65, 035406 (2002).

[23] B. Dillmann, Ph.D. thesis, Ruhr University, 1996.

[24] Cytochrome P-450: Structure, Mechanisms, and Biochemistry, edited by P.R. Ortiz de Montellano (Plenum, New York, 1986). 